\title{
The X-ray structure of an anti-tumour antibody in complex with antigen
}

Philip D. Jeffrey, Jürgen Bajorath, Chieh Ying Y Chang, Dale Yelton, Ingegerd Hellström, Karl Erik Hellström and Steven Sheriff Nature Structural Biology 2, no. 6, 466-471 (1995).

On pg. 71 beneath the heading 'Structural analysis', the Protein Data Bank accession numbers should read: 1CLY and 1CLZ.

\section{Amino-acid substitutions in a surface turn modulate protein stability}

Paul F. Predki, Vishal Agrawal, Axel T. Brünger and Lynne Regan

Nature Structural Biology 3, no. 1, 54-58 (1996).

In Table 3, the free- $R$ factor should be 0.272 .

\section{Insights into protein adaptation to a saturated salt environment from the crystal structure of a halophilic $2 \mathrm{Fe}-2 \mathrm{~S}$ ferredoxin}

Felix Frolow, Michal Harel, Joel L Sussman, Moshe Mevarech and Menachen Shoham Nature Structural Biology 3, no. 5, 452-458 (1996).

In Table 2, row 2, entry HmMDH, the values for accessible surface area and net charge density should appear as they do below:

\begin{tabular}{ccc}
\hline \multicolumn{2}{c}{$\begin{array}{c}\text { Table } 2 \text { The most negatively charged water-soluble proteins in } \\
\text { the Protein Data Bank }\end{array}$} \\
\hline & Accessible surface area & Net charge \\
& $\left(\AA^{2}\right)$ & density $\times 10^{3}\left(\AA^{-2}\right)$ \\
$\mathrm{HmMDH}^{1}$ & 13431 & -2.4 \\
\hline
\end{tabular}

\section{erratum}

\section{Detection of rare partially folded molecules in equilibrium with the native conformation of RNase H}

Aaron K. Chamberlain, Tracy M. Handel and Susan Marqusee Nature Structural Biology, 3, no. 9, 782-787 (1996).

Figure $1 b$ was inadvertently misprinted. The version to the right is as it should have appeared in the September issue of Nature Structural Biology.

Fig. 1 RNase $\mathrm{H}^{*}$ separates into three regions based on the stability of protons to hydrogen exchange. $b$, The three regions with differing stabilities shown on a ribbon diagram of the RNase $\mathrm{H}$ crystal structure ${ }^{8}$ (INSIGHTH, Biosym Technologies). The regions consist of: helices A and D (blue), helix B and strand 4 (green), and the remaining protons in helices C, E and strands 1, 2, 3, and 5 (red).

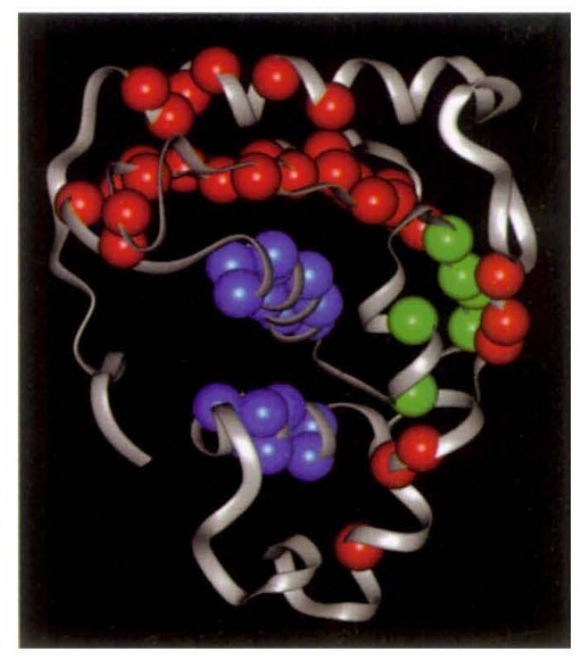

